\title{
Selective loss of vascular smooth muscle cells in the retinal microcirculation of diabetic dogs
}

\author{
T A Gardiner, A W Stitt, H R Anderson, D B Archer
}

Department of
Ophthalmology, The
Queen's University of
Belfast, Belfast
T A Gardiner
A W Stitt
H R Anderson
D B Archer
Correspondence to:
Professor D B Archer,
Department of
Ophthalmology, The Queen's
University of Belfast, Institute
of Clinical Science, Grosvenor
Road, Belfast BT12 6BA,
Northern Ireland.
Accepted for publication
26 August 1993

Abstract

This study was undertaken to further characterise the fine structural changes occurring in the retinal circulation in early diabetes. The eyes of eight alloxan/streptozotocin and three spontaneously diabetic dogs were examined by trypsin digest and electron microscopy after durations of diabetes of between 1 and 7 years. Basement membrane (BM) thickening in the retinal capillaries was the only obvious fine structural change identified during the first 3 years of diabetes and was established within 1 year of induction. Widespread pericyte loss was noted after 4 years of diabetes and was paralleled by loss of smooth muscle (SM) cells, in the retinal arterioles. SM cell loss was most obvious in the smaller arterioles of the central retina. No microaneurysms were noted in the experimental diabetic dogs with up to 5 years' duration of diabetes but were widespread in a spontaneously diabetic animal at 7 years. This study has shown that SM cell loss, a hitherto unrecognised feature of diabetic microangiopathy, accompanies pericyte loss in the retinal circulation of diabetic dogs.

(Brf Ophthalmol 1994; 78: 54-60)

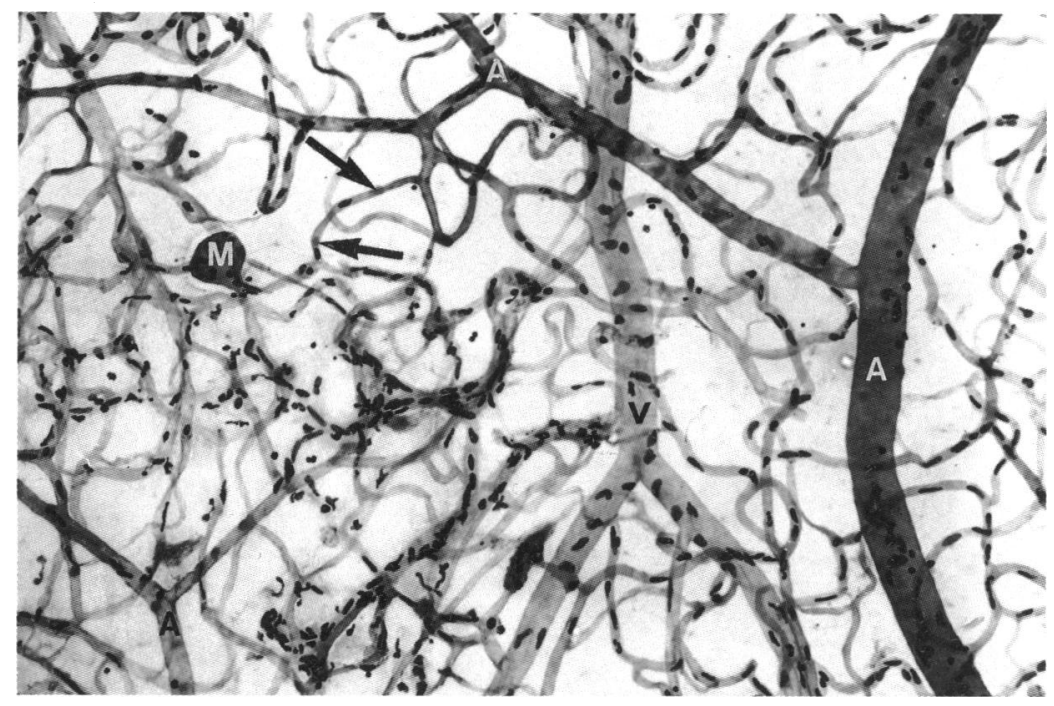

Figure 1A Spontaneously diabetic dog retina (7 years diabetic). The vasculature in the central retina shows a microaneurysm (M), acellular capillaries (black $A)$, and pericyte 'ghosts' stained red with periodic acid Schiff (arrows). The precapillary arteriole (white A) is almost devoid of smooth muscle (SM) cells. Venule (V). Magnification $\times 240$.

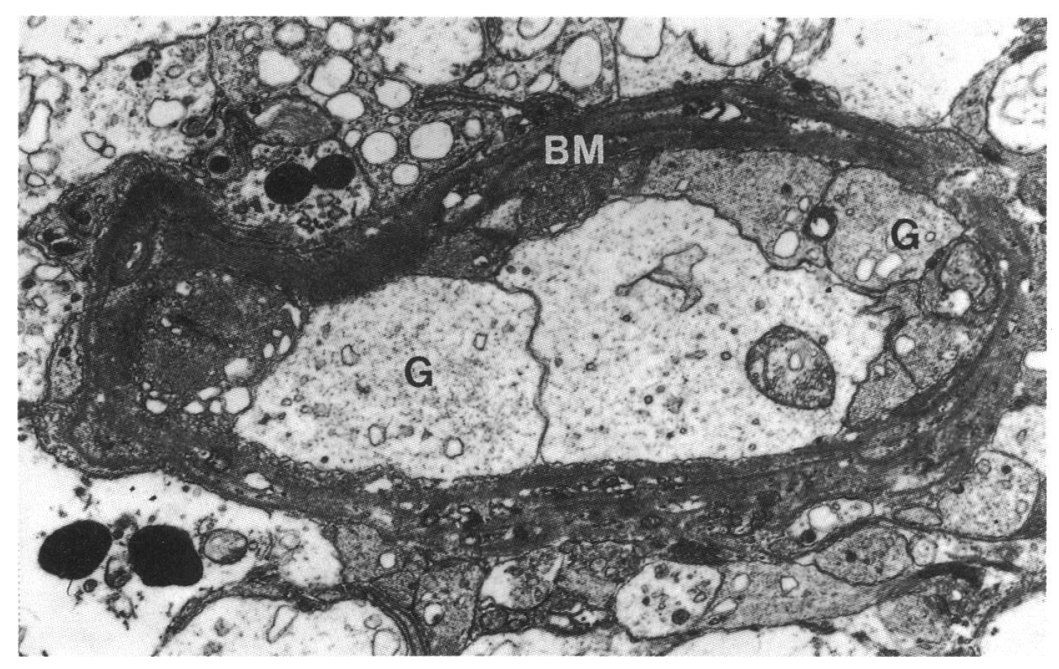

Figure $1 B$ Spontaneous diabetic dog (7 years diabetic). Acellular capillary from central retina adjacent to region depicted in Figure $1 A$. The residual basement membrane $(B M)$ tube is filled by processes of hypertrophic glial cells $(G)$. Magnification $\times 7300$.
The diabetic dog, whether spontaneous ${ }^{1}$ or drug induced, ${ }^{2}$ represents one of the best models of human diabetes, and faithfully reproduces all of the recognised features of preproliferative retinal microangiopathy - that is, thickening of the vascular basement membranes (BM), pericyte loss, microaneurysm formation, and capillary closure. ${ }^{3}$ As most of these features are associated with the capillary bed the majority of recent studies have focused on that portion of the retinal circulation with less emphasis on the changes occurring in the larger vessels. This report chiefly concerns the selective loss of smooth muscle cells in the retinal arteries.

\section{Materials and methods}

We obtained the eyes of three spontaneously diabetic dogs from local veterinary practitioners and studied the retinal vasculatures by light microscopy following trypsin digestion. Selected areas were evaluated by electron microscopy. These were compared with eyes from eight alloxan/streptozotocin diabetic dogs and 10 agematched control animals. Three 6-year-old beagles were the closest match available as controls for the 7 year spontaneous diabetic dog.

Beagle dogs weighing between 12 and $14 \mathrm{~kg}$ were rendered diabetic by a single intravenous injection of a cocktail containing alloxan $(40 \mathrm{mg} /$ $\mathrm{kg}$ ) and streptozotocin $(35 \mathrm{mg} / \mathrm{kg})$ after the method of Black $e a^{4}$ and managed according to the regimen described by Anderson et al. ${ }^{5}$ The blood sugar of the dogs after an overnight fast was maintained between 15 and $20 \mathrm{mmol} / 1$ by a single daily subcutaneous injection of Insulatard isophane insulin given immediately before breakfast. The animals were maintained on a diet of tripe and biscuit supplemented with vitamins and minerals. One dog was sacrificed by an intravenous injection of sodium pentobarbitone at each of the following time intervals following induction of diabetes: 6 months, 1 year, 2 years, 3 years. Four animals were sacrificed between 4 and 5 years after induction. The eyes were 


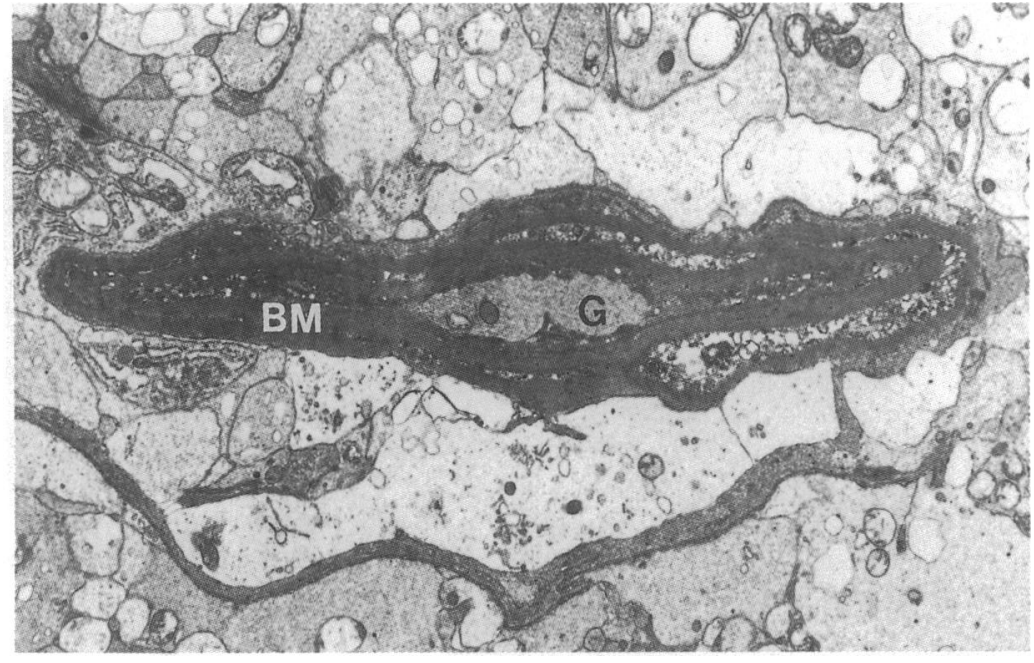

Figure 1C Spontaneous diabetic dog (7 years diabetic). An acellular capillary from the same region as that depicted in Figure $1 B$ consists of a collapsed basement membrane $(B M)$ tube. $A$ glial process $(G)$ fills the remnant of the vascular lumen. Magnification $\times 5500$.

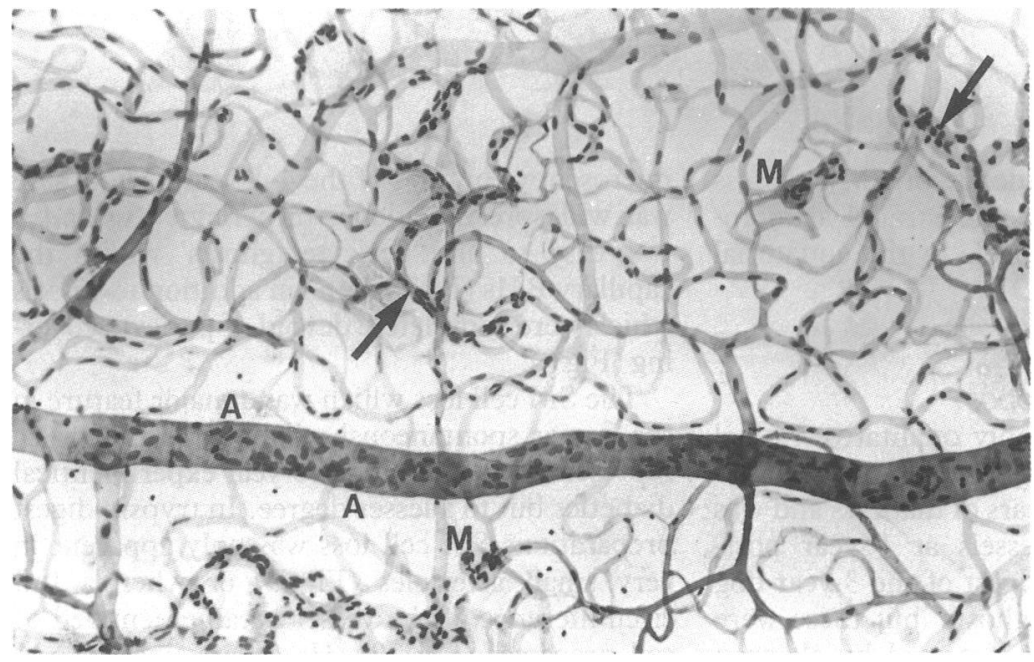

Figure 2 Spontaneously diabetic dog retina (7 years diabetic). A second order retinal arteriole $(A)$ shows widespread loss of smooth muscle (SM) cells. The capillary bed supplied by the arteriole contains microaneurysms $(\boldsymbol{M})$, acellular capillaries, and dilated shunt-like channels (arrows). Magnification $\times 155$.

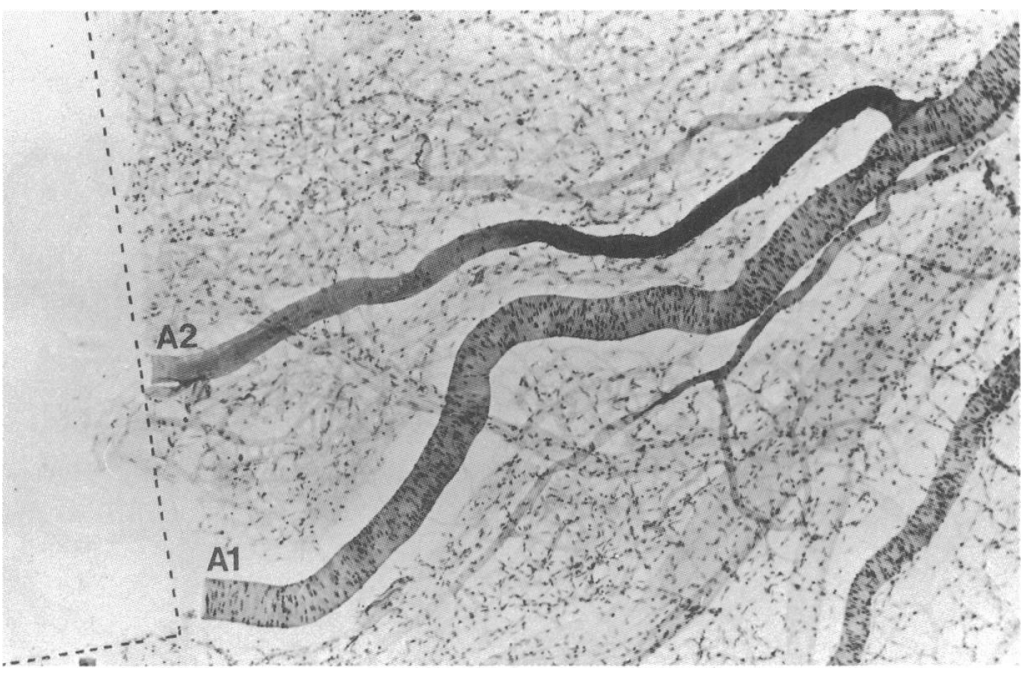

Figure $3 A$ Spontaneously diabetic dog ( 7 years diabetic). A first order retinal artery $(A 1)$ appears normal. A second order branch (A2) shows few stained smooth muscle (SM) cell nuclei and the vessel wall stains deeply with periodic acid Schiff. Broken line - site of electron microscope sample. Magnification $\times 80$. enucleated and, following removal of the anterior segment and vitreous, the right eye cup was fixed for electron microscopy by overnight immersion in $2.5 \%$ glutaraldehyde in $0.1 \mathrm{M}$

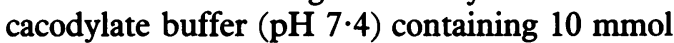
magnesium chloride. Selected areas from the central and peripheral retina were post-fixed in $2 \%$ osmium tetroxide in $0 \cdot 1 \mathrm{M}$ cacodylate buffer, dehydrated in ascending concentrations of ethanol, and embedded in Spurr's resin. The left eye of each animal was fixed overnight in 10\% formalin in $0.1 \mathrm{M}$ phosphate buffer and the neural retina was dissected off for trypsin digestion according to the method of Kuwabara and Cogan. ${ }^{6}$ The trypsin digests were stained with periodic acid Schiff (PAS) and haematoxylin. The eyes of the spontaneous diabetic dogs were all received in $10 \%$ formalin in $0.1 \mathrm{M}$ phosphate buffer. Selected areas of the retinas were carefully dissected and refixed in glutaraldehyde for electron microscopy as described above. The remainder of the retinas were subjected to trypsin digestion.

\section{Results}

SPONTANEOUSLY DIABETIC DOGS

Electron microscopy of the retinas of two dogs which had been diagnosed as diabetic 11 and 15 months before sacrifice showed vascular BM thickening but no other microvascular abnormality. The retinal digest of the third animal, which had survived for 7 years following the diagnosis of diabetes, showed widespread pericyte loss, acellular capillaries, and microaneurysm formation in the central retina (Fig 1). This region also showed dilated shunt-like channels which may have represented the vascular entities referred to as intraretinal microvascular abnormalities (IRMA). It was notable that the most severely affected capillary beds were supplied by arteries and arterioles which demonstrated a gross degeneration of the smooth muscle (SM) cells in the vessel walls. In vessels where SM cell loss was widespread the normal circumferential SM cell coat was often reduced to a few randomly oriented cells which, when superimposed on the intact endothelial layer, gave the vessels a venous appearance in digest preparations (Fig 2). In extreme cases the greater part of the arterial wall was atrophic and replaced by a dense sheath which appeared white and fibrous under the dissecting microscope and stained deep red with PAS obscuring the nuclear stain of the arterial endothelium within (Fig 3A). Electron microscopic samples from such vessels revealed a patent lumen perfused by blood and lined by an intact layer of endothelial cells (Figs $3 B, C)$. The vessel walls were composed of a dense sheath of fine collagen fibres (Fig 3C). In regions where the SM cell loss was less advanced trypsin digests showed focal collars of PAS stained SM cell 'ghosts' in association with fusiform dilatations of the vessel walls (Fig 4). Although discrete regions of SM cell loss could be recognised in the largest retinal arteries (Fig 5 ), the change was most obvious in second order to precapillary arterioles in the central retina. Trypsin digests from the three 6-year-old con- 
Figure 3B Electron microscopic section through wall of vessel Al depicted in Figure $3 A$ shows an intact endothelium $(E)$ and normal smooth muscle (SM) cells. Lumen $(L)$. Magnification $\times 6700$.
Figure 3C Vessel A2 depicted in Figure $3 A$. Endothelium $(E)$ is intact and lumen $(L)$ is perfused with blood. Vessel wall shows a dense layer of fine collagen fibrils (CF). A surviving smooth muscle $(S M)$ cell is seen adjacent to the endothelium.

Magnification $\times 4250$.

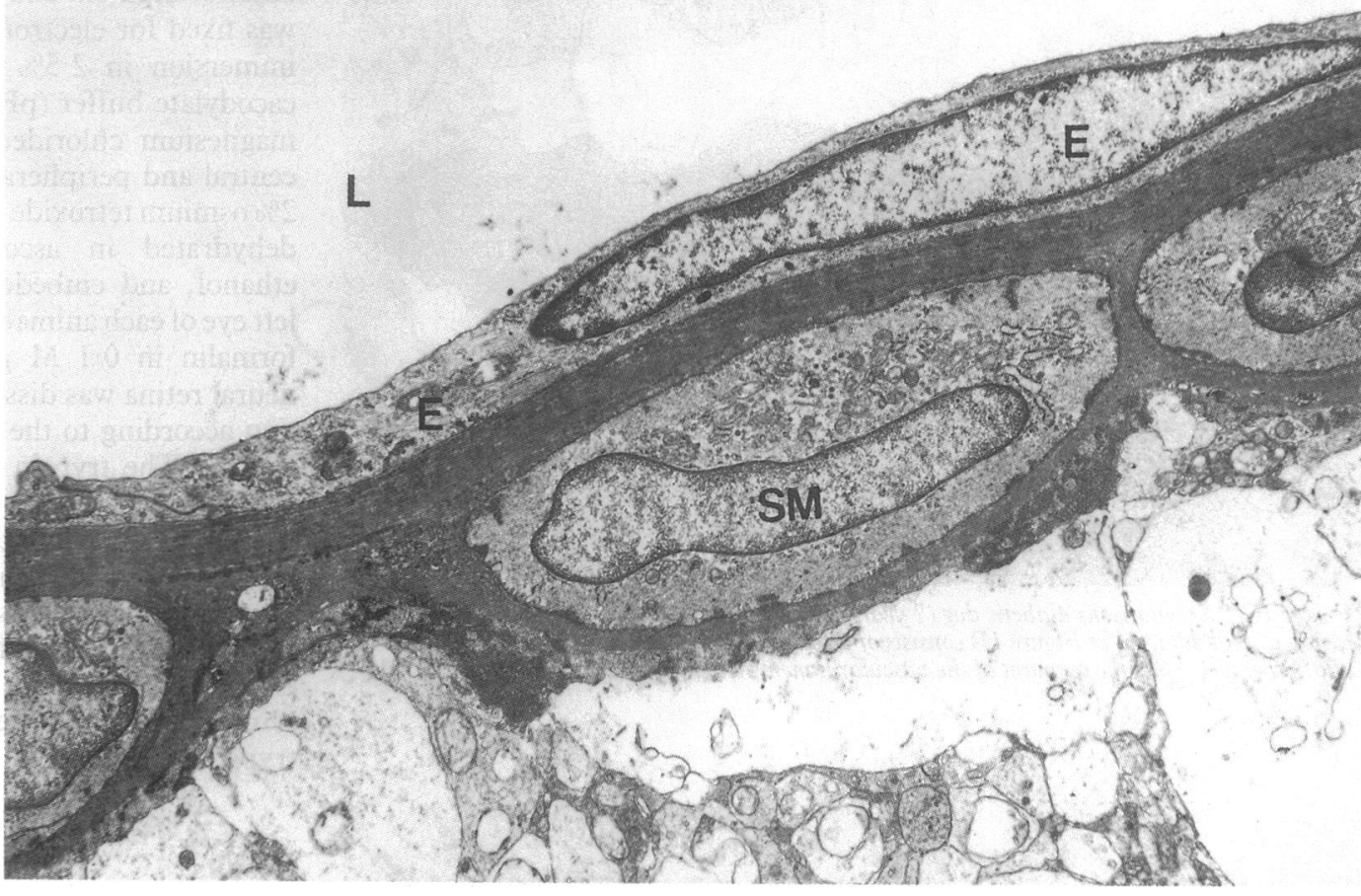

trol dogs showed no evidence of SM cell loss although one specimen demonstrated a microaneurysm in a small arteriole of the equatorial retina (Fig 6).

\section{EXPERIMENTAL DIABETIC DOGS}

BM thickening was the only qualitative retinal microvascular abnormality in experimental diabetic dogs with up to 3 years of diabetes and was recognisable in some vessels at 1 year postinduction. The trypsin digest of the 3 year dog revealed a few pericyte 'ghosts' but these were too scattered to be easily detected by electron microscopy. In dogs of the 4-5 year group there was widespread evidence of pericyte loss and it was easy to find pericyte 'ghosts' within the capillary BMs (Figs 7A, B) in addition to vessels which were completely devoid of pericyte covering (Fig 8).

The SM cell loss which was a major feature in the 7 year spontaneously diabetic dog was also represented in all of the 4-5 year experimentical diabetics but to a lesser degree. In trypsin digest preparations SM cell loss was only apparent in very small arterioles (Fig 9) or when a full circumference of the vessel became denuded of cell processes (Fig 10). However, singular SM 


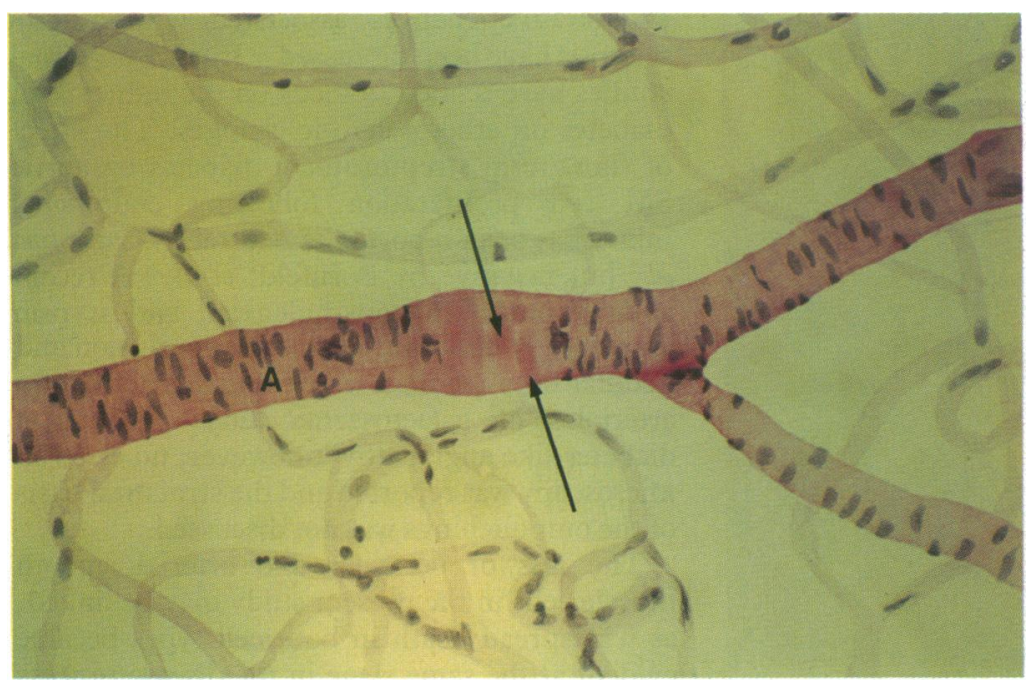

Figure 4 Spontaneously diabetic dog ( 7 years diabetic). A second order retinal arteriole $(A)$ shows fusiform dilatation at site of smooth muscle (SM) cell loss. SM cell 'ghosts' (arrows) stain red with periodic acid Schiff. Magnification $\times 310$.

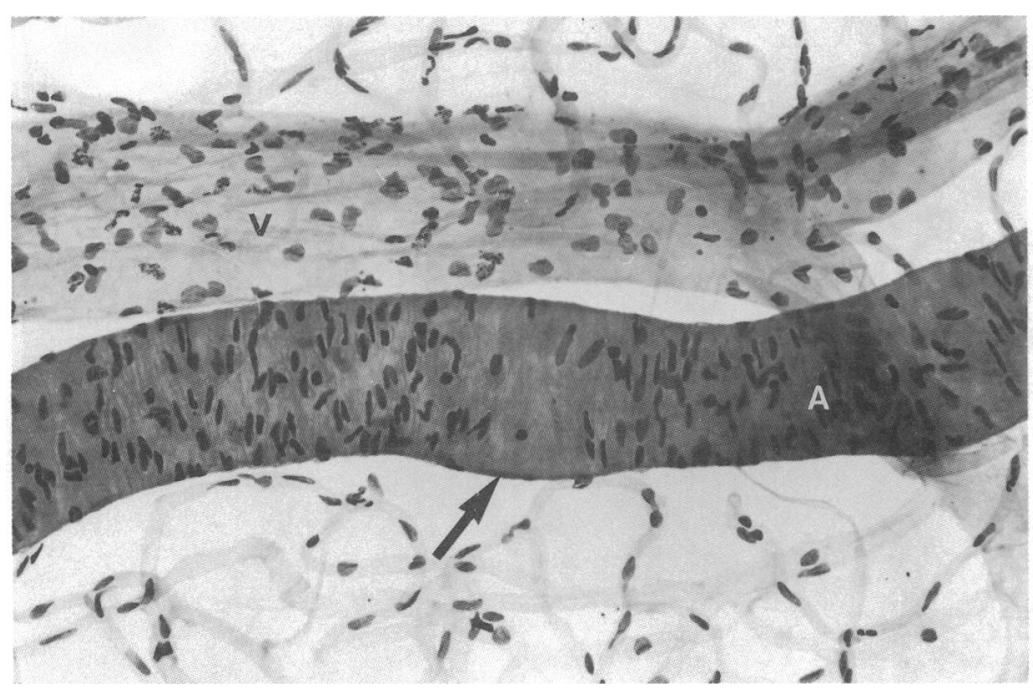

Figure 5 Spontaneously diabetic dog (7 years diabetic). A first order retinal artery $(A)$ shows a focal collar of smooth muscle $(S M)$ cell loss $($ arrow). Vein $(V)$. Magnification $\times 240$.

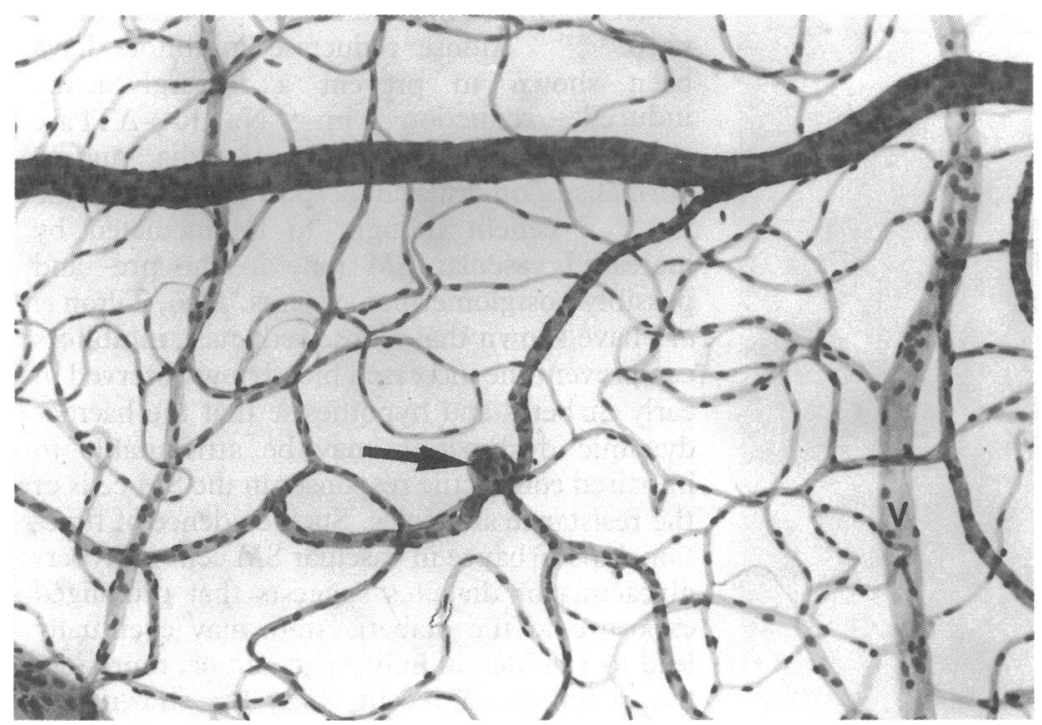

Figure 6 Control dog (6 years). A microaneurysm (arrow) is present in a small arteriole of the equitorial retina. Venule $(V)$. Magnification $\times 160$. 'ghosts', which were filled with lysosomal debris identical to that in pericyte 'ghosts', were a frequent electron microscopic inclusion within the BMs of many retinal arteries and arterioles (Figs 11A, B).

\section{Discussion}

This study has confirmed that BM thickening is the first obvious morphological change in the retinal microvasculature of diabetic dogs. Pericyte degeneration was not observed in the present study until after 3 years of diabetes but appeared to progress steadily after that time, being sufficiently widespread in the 4-5 year animals as to be easily detectable in electron microscope samples. Current thinking on the selective pericyte demise in diabetes emphasises the differential in polyol pathway activity between pericytes and vascular endothelial cells and suggests that in hyperglycaemia excess glucose in pericytes is efficiently converted to its relatively non-diffusable polyalcohol, sorbitol, the presence of which leads to major biochemical disturbance and eventual cell death. ${ }^{78}$ This hypothesis is supported by a number of studies which have shown that inhibitors of the polyol pathway prevent or reduce $B M$ thickening and significantly retard pericyte loss and microaneurysm formation in animal models of diabetes $^{9}$ and diabetes-like angiopathies, ${ }^{1011}$ although some reports are contradictory. ${ }^{12} 13$ The broad spectrum of activities of the drugs used in polyol pathway inhibition has led some workers to suggest that their beneficial effects may be related to other putative roles as free radical scavengers ${ }^{14}$ or as chelating agents for transition metals involved in the generation of oxidising free radicals. ${ }^{15}$ These workers question the involvement of aldose reductase, the principal enzyme of the polyol pathway, ascribing the observed production of sorbitol to the autooxidation of glucose. ${ }^{16}$ Such doubts concerning the activity of aldose reductase have been further substantiated by a recent study showing that the active site of the enzyme resides in a highly hydrophobic pocket, inappropriate for the catalysis of polar substrates such as hexoses. ${ }^{17}$ Nevertheless, the relatively high polyol pathway activity in pericytes ${ }^{18-20}$ remains an important identifiable difference between them and endothelial cells and goes some way towards explaining the differential in their tolerances to the diabetic state.

The loss of SM cells from the walls of retinal arteries and arterioles was first noticed in the 7 year spontaneously diabetic dog but was sufficiently prevalent in 4-5 year experimental animals to be easily detectable by either trypsin digest or electron microscopy. Such lesions should not be confused with mechanical damage which can occur in trypsin digest preparations during the mounting procedure. Artefactual crushing of arterial walls produces deranged and broken cell nuclei but never PAS positive SM cell 'ghosts', the electron microscopic counterparts of which are easily located in ultrathin sections. Degeneration of vascular smooth muscle has not been previously reported in diabetic animals and in human disease only the 


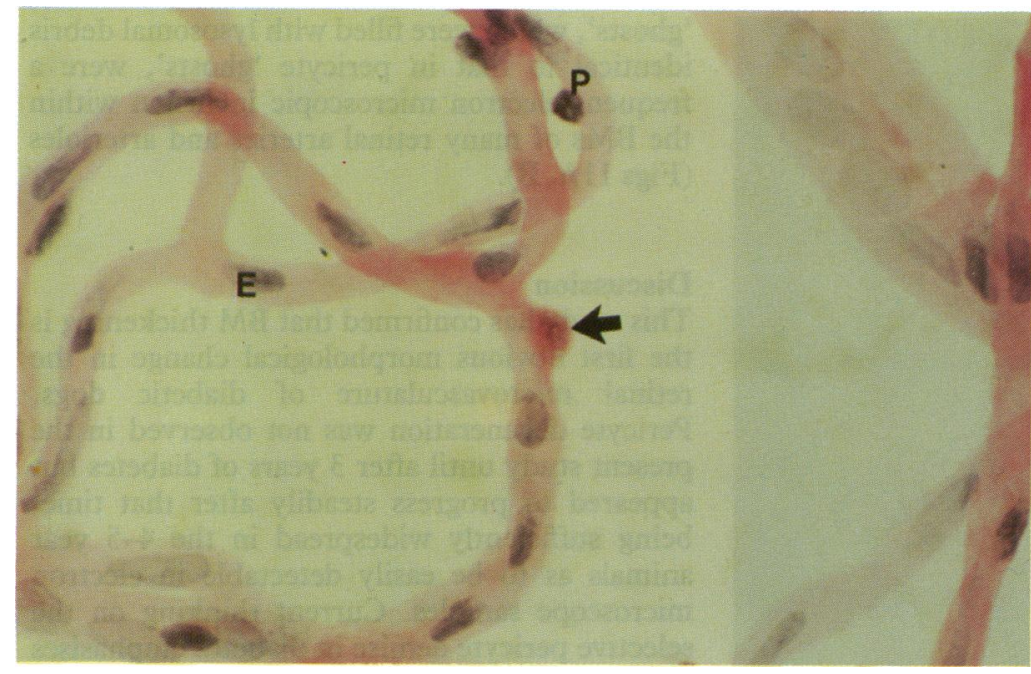

Figure 7A Experimental diabetic dog (5 years diabetic). A pericyte 'ghost' stains deep red with periodic acid Schiff (arrows). Normal pericyte nucleus $(P)$. Endothelial cell nuclei $(E)$. Magnification $\times 1250$. proliferative changes associated with atherosclerosis have been discussed..$^{21}$ Likewise, animal studies have tended to focus on the influence of diabetes on atherosclerotic changes. The effect of short term streptozotocin diabetes on aortic SM cell proliferation following endothelial injury has been reported as neutral by Capron $e t$ $a l^{22}$ but negative by Bornfeldt et al. ${ }^{23} \mathrm{~A}$ recent angiographical, histopathological, and trypsin digest study has reported vascular occlusion and nodular outpouchings in the retinal arteries and arterioles of galactosaemic dogs showing a diabetes-like angiopathy ${ }^{24}$; however, no electron microscopy was reported and the structural basis of the outpouchings was not discussed.

The loss of pericytes and arterial smooth muscle cells in the present study may be linked, as widespread death in both cell types became evident at the same stage in the disease process and both show high polyol pathway activity

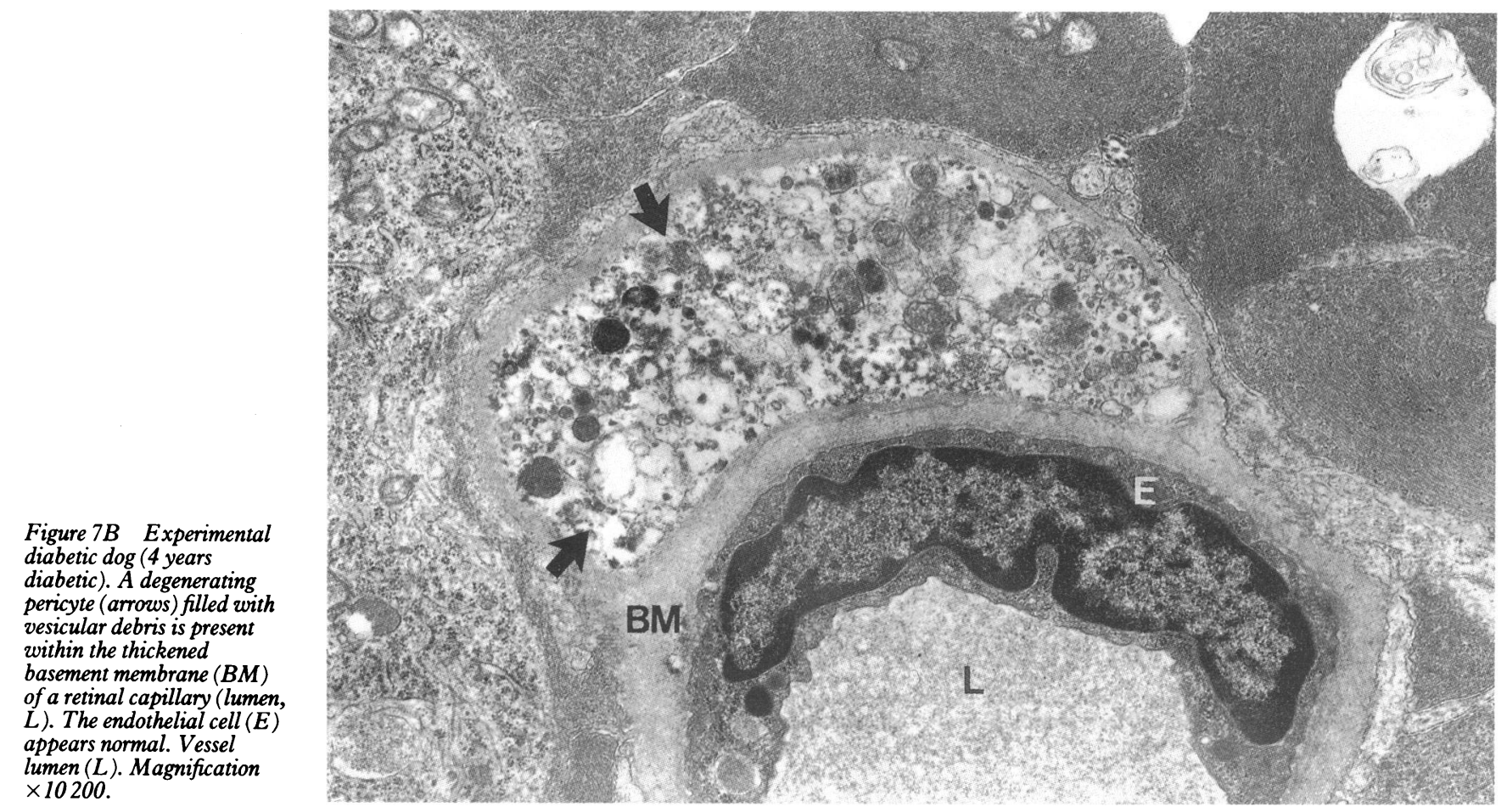

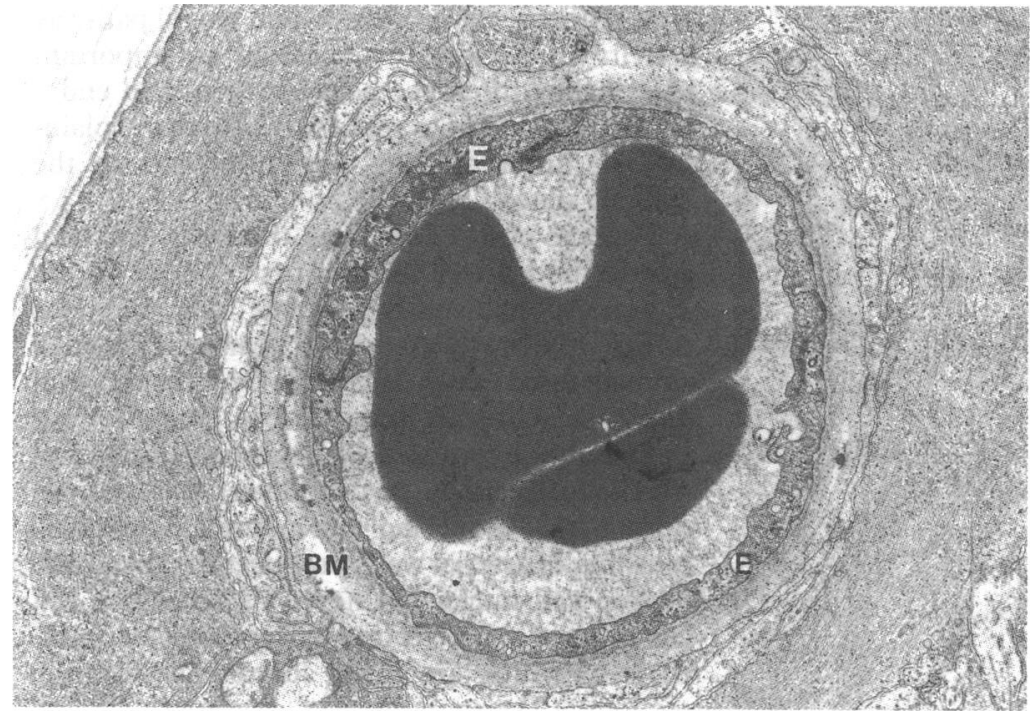

Figure 8 Experimental diabetic dog (5 years diabetic). A dilated retinal capillary shows complete loss of normal pericyte covering. The endothelium $(E)$ is intact. Magnification $\times 6300$. under conditions of simulated hyperglycaemia in vitro. ${ }^{182025-27}$ Aldose reductase inhibitors have been shown to prevent a hyperglycaemia induced reduction in $\left(\mathrm{Na}^{+}, \mathrm{K}^{+}\right)$-ATPase activity in rabbit aortic intima media ${ }^{28}$ and to normalise glomerular hyperperfusion in diabetic rats, ${ }^{29}$ a benefit thought to be mediated by increased vascular SM tone in the pre- and possibly postglomerular systems. Also, Tilton $e t$ $a l^{30}$ have shown that aldose reductase inhibitors can prevent the increased blood flow observed in early diabetes and hypothesise that the haemodynamic dysfunction may be attributable to impaired contractile responses in the SM cells of the resistance arterioles. Such evidence of functional disturbance in vascular SM cells in hyperglycaemia or diabetes suggests that prolonged exposure to the diabetic state may eventually lead to a reduction in lifespan and/or, reproductive potential. A recent study has shown that vascular SM cells demonstrate an autoregulatory mechanism which reversibly reduces glucose 


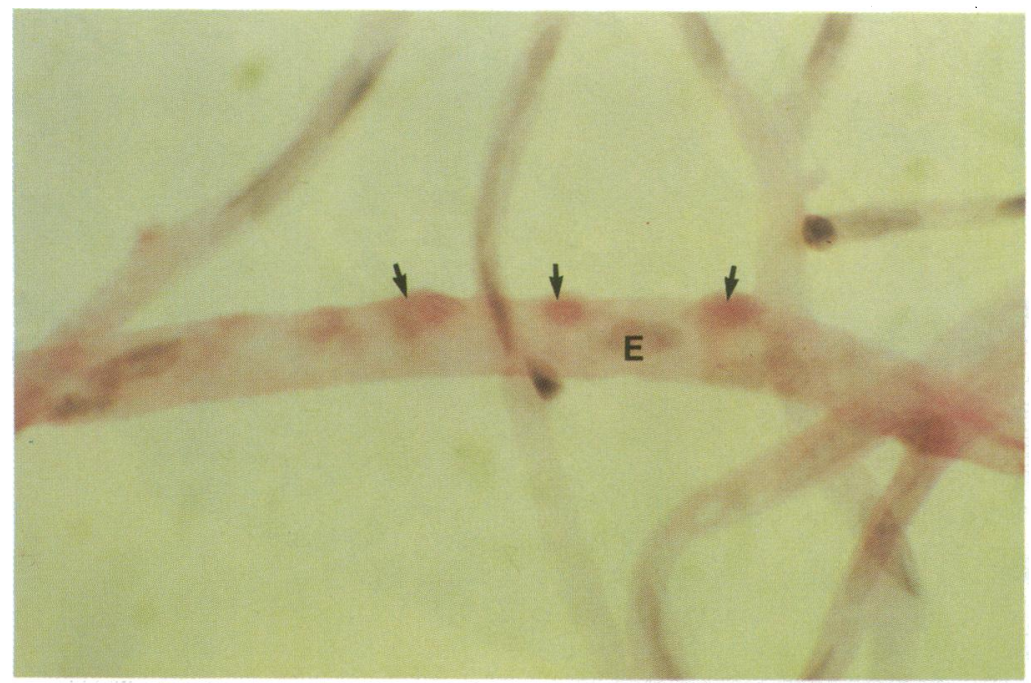

Figure 9 Experimental diabetic dog (5 years diabetic). A precapillary arteriole shows extensive loss of smooth muscle (SM) cells. SM cell 'ghosts' (arrows) stain red with periodic acid $S c h i f f$. Endothelial cell nuclei $(E)$ are present within the vessel. Magnification $\times 1250$.

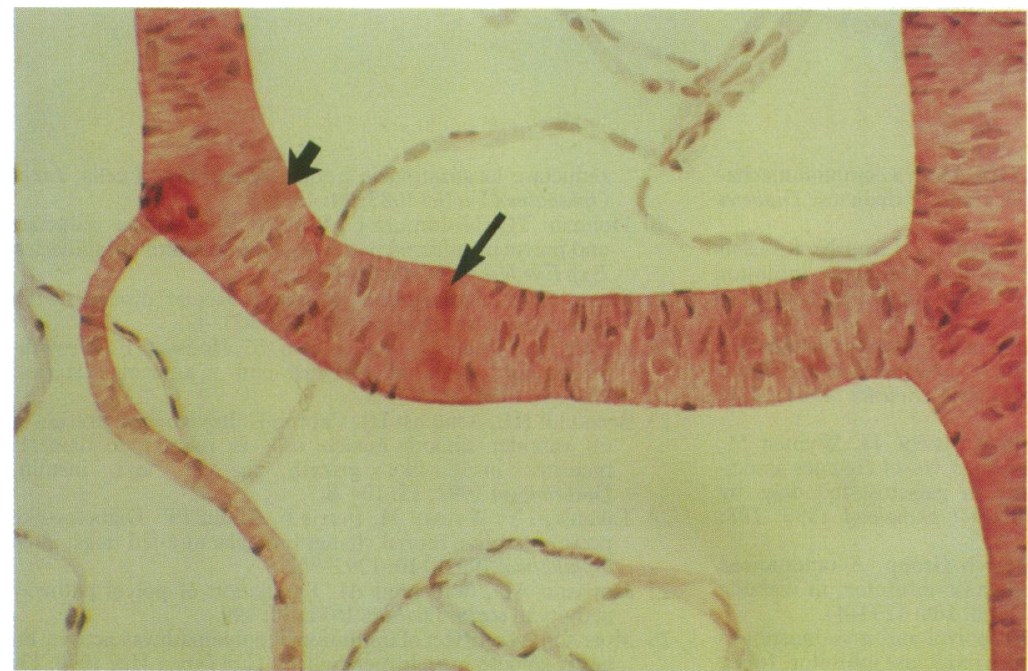

Figure 10 Experimental diabetic dog (5 years diabetic). Smooth muscle (SM) cell 'ghosts', are present at dilatation in a second order arteriole (arrow). Another dilatation is present at junction with a precapillary arteriole (large arrow head). Magnification $\times 300$. transport when the cells are exposed in vitro to high glucose media for 24 hours. ${ }^{31}$ Although such autoregulation may protect SM cells from the adverse effects of high glucose in the short term, the arterial SM cells in the present study had been exposed to chronic hyperglycaemia for several years.

Microaneurysms were not seen in any of the experimental diabetic animals but were common in the 7 year spontaneously diabetic dog, notably in vascular beds where the arterial supply showed obvious depletion of smooth muscle cells. These observations suggest that the distension of the vascular wall at sites of microaneurysm formation may have resulted from lack of arterial control of the blood flow in vessels already compromised by loss of SM cells or pericytes.

As we do not have access to well preserved human retina at relevant stages in the disease process we have been unable to assess the significance of these observations to the pathogenesis of diabetic microangiopathy in human disease.

1 Patz A, Maumenee AE. Studies on diabetic retinopathy. I: Retinopathy in a dog with spontaneous diabetes mellitus. Am F Ophthalmol 1962; 54: 532-41.

2 Engerman RL, Bloodworth JMB Jr. Experimenta diabetic retinopathy in dogs. Arch Ophthalmol 1965; 73: 205-10.

3 Engerman R, Finkelstein D, Aquirre G, Diddie KR, Fox RR, Frank RN, et al. Animals appropriate for studying diabetes mellitus and its complications: ocular complications. Diabetes 1982; 31 (suppl 1): 82-8.

4 Black HE, Rosenblum IY, Capen CC. Chemically induced (streptozotocin-alloxan) diabetes mellitus in the dog. $A m \mathcal{F}$ Pathol 1980; 98: 295-305.

5 Anderson HR, Stitt AW, Gardiner TA, Lloyd SJ, Archer DB. Induction of alloxan/stretozotocin diabetes in dogs. Lab Animals 1993; 27: 281-5.

6 Kuwabara T, Cogan DG. Studies of retinal vascular patterns. Part 1: Normal architecture. Arch Ophthalmol 1960;64: 904 11.

7 Kinoshita JH. Aldose redose in the diabetic eye. XLIII Edward Jackson memorial lecture. Am f Ophthalmol 1986; 102: 685-92.
Figure $11 A$ Experimental diabetic dog (4 years diabetic). A smooth muscle (SM) cell 'ghost' (arrow) filled with vesicular debris is present within the wall of $a$ large retinal arteriole (lumen, $L$ ). Processes of normal $S M$ cells are also
present. Endothelium $(E)$. Magnification $\times 5950$.

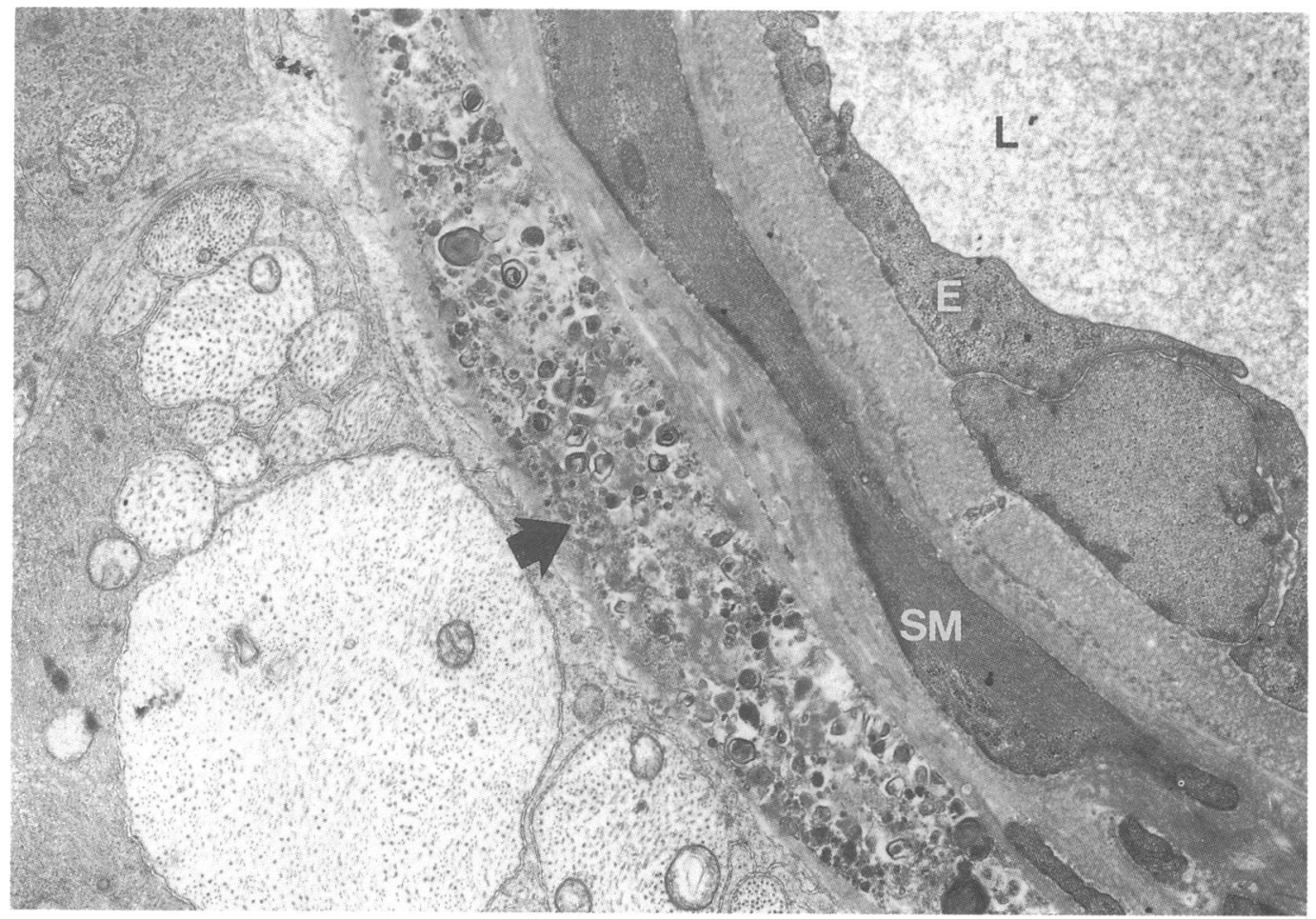


Figure $11 B$ Experimental diabetic dog (4 years diabetic). Wall of large retinal arteriole shows junction (arrow) between normal smooth muscle $(S M)$ cell process $(S M P)$ and $S M$ cell 'ghost' filled with vesicular debris (large arrow head). Endothelium $(E)$.

Lumen $(L)$. Magnification $\times 10080$

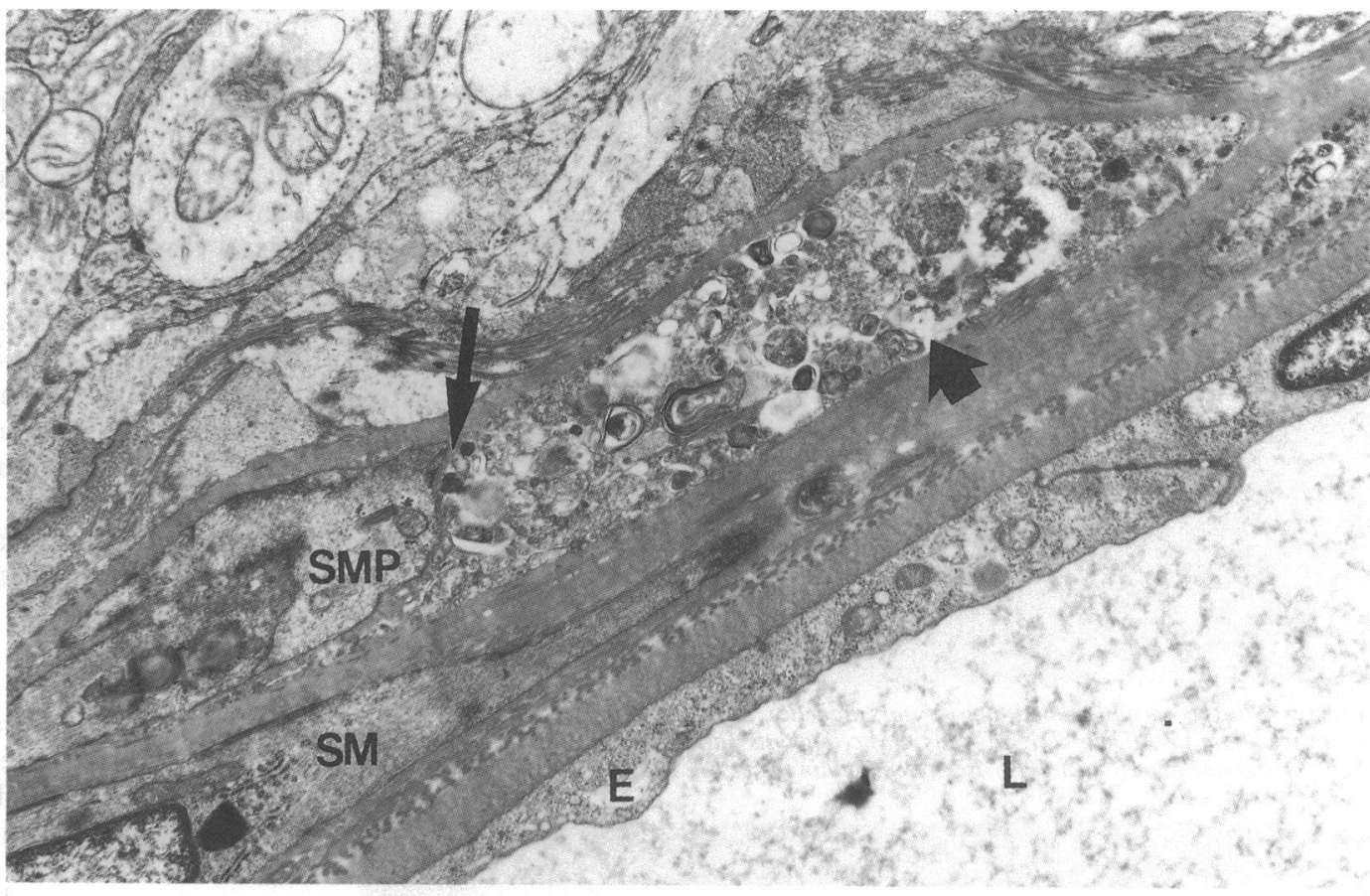

8 Winegrad AI. Banting Lecture 1986. Does a common mechanism induce the diverse complications of diabetes? Diabetes 1986; 36: 396-406.

9 McCaleb ML, McKean ML, Hohman TC, Laver N, Robison WG. Intervention with the aldose reductase inhibitor tolrestat in renal and retinal lesions of streptozotocin diabetic rats. Diabetologia 1991; 34: 695-701.

10 Robison WG, Kador PF, Konoshita JH. Retinal capillaries: basement membrane thickening by galactosemia prevented with an aldose reductase inhibitor. Science 1983; 221 : 1177-9.

11 Kador PF, Akagi Y, Takahashi Y, Ikebe H, Wyman M, Kinoshita JH. Prevention of retinal vessel changes associated with diabetic retinopathy in galactose-fed dogs by aldose reductase inhibitors. Arch Ophthalmol 1990; 108: 1301-9.

12 Sorbinil Retinopathy Trial Research Group. A randomised trial of sorbinil, an aldose reductase inhibitor, in diabetic trial of sorbinil, an aldose reductase inhibitor, in

13 Kern TS, Engerman RL. Retinal polyol and myo-inositol in galactosemic dogs given an aldose reductase inhibitor. Inves Ophthalmol Vis Sci 1991; 32: 3175-7.

14 Stevens VJ, Rouzer CA, Monnier VM, Cerami A. Diabetic cataract formation; potential role of glycosylation of lens proteins. Proc Natl Acad Sci 1978; 75: 2918-22.

15 Jiang ZY, Zhou QL, Eaton JW, Koppenol WH, Hunt JV, Wolff SP. Spirohydantoin inhibitors of aldose reductase inhibit iron and copper-catalysed ascorbate oxidation in vitro. Biochem Pharmacol 1991; 42: 1273-8.

16 Wolff SP. The potential role of oxidative stress in diabetes and its complications: novel implications for theory and therapy. In: Crabbe MJC, ed. Diabetic complications. Edinburgh: In: Crabbe MJC, ed. Diabetic complicat

17 Wilson DK, Bohren KM, Gabbay KH, Quiocho FA. An unlikely sugar substrate site in the $1.65 \AA$ structure of the human aldose reductase holoenzyme implicated in diabetic complications. Science 1992; 257: 81-4.

18 Buzney SM, Frank RN, Varma SD. Aldose reductase in retinal mural cells. Invest Ophthalmol Vis Sci 1977; 16: 392-6.

19 Akagi Y, Kador PF, Kuwabara T, Kinoshita JH. Aldose reductase localization in human retinal mural cells. Invest Ophthalmol Vis Sci 1983; 24: 1516-9.

20 Hohman TC, Nishimura C, Robison WG. Aldose reductase and polyol in cultured pericytes of human retinal capillaries. Exp Eye Res 1989; 48: 55-60.

21 Ganda OMP. Pathogenesis of macrovascular disease in the human diabetic. Diabetes 1980; 29: 931-42.

22 Capron L, Jarnet J, Kazandjian S, Housset E. Growthpromoting effects of diabetes and insulin on arteries. Diabetes 1986; 35: 973-8.

23 Bornfeldt KE, Arnqvist HJ, Capron L In vivo proliferation of rat vascular smooth muscle cells in relation to diabetes mellitus insulin-like growth factor-1 and insulin.

24 Takahashi Y, Wyman M, Ferris F, Kador PF. Diabetes-like preproliferative retinal changes in galactose-fed dogs. Arch

25 Morrison AD, Winegrad AI. Regulation of polyol pathway activity in aorta. Diabetes 1971; 20: 329

26 Morrison AD. Effect of inhibition of polyolpathway activity on aortic smooth muscle metabolism. Clin Invest Med 1990; 13 : 119-22.

27 Tawata M, Ohtaka M, Hosaka Y, Onaya T. Aldose reductase mRNA expression and its activity are induced by glucose in fetal rat aortic smooth muscle (A10) cells. Life Sci 1992; 51 : $719-26$

28 Simmons DA, Winegrad AI. Mechanisms in rabbit aorta fo hyperglycaemia-induced alteractions in angiotensin II and hyperglycaemia-induced alteractions in angiotensin

29 Bank N, Mower P, Aynedjian HS, Wilkes BM, Silverman S. Sorbinil prevents glomerular hyperperfusion in diabetic Sorbinil prevents glomerular hyperpert

30 Tilton RG, Chang K, Pugliese G, Eades DM, Province MA Sherman WR, et al. Prevention of hemodynamic and vascular albumin filtration changes in diabetic rats by aldose reductase inhibitors. Diabetes 1989; 38: 1258-70.

31. Kaiser N, Sasson S, Feener EP, Boukobza-Vardi N, Higash $\mathrm{S}$, Moller DE, et al. Differential regulation of glucose transport and transporters by glucose in vascular endothelial and smooth muscle cells. Diabetes 1993; 42: 80-9. Diabetologia 1992; 35: 104-8. Ophthalmol 1992; 110: 1295-302. 